\title{
Using schiff base method for protecting amino acids and modified in vitro method for measuring rumen protected amino acids
}

\author{
M. Mazinani ${ }^{1}$, A.A. Naserian' ${ }^{1}$, B. Rude ${ }^{2}$, R. Valizadeh $^{1}$ and A. Tahmasbi ${ }^{1}$ \\ ${ }^{1}$ Department of Animal Sciences, Faculty of Agriculture, Ferdowsi University of Mashhad, Mashhad, Iran, ${ }^{2}$ Department of \\ Animal and Dairy Sciences, Faculty of Agriculture, Mississippi State University, Starkville, USA
}

\begin{tabular}{l} 
Article information \\
\hline Article history: \\
Received March 9, 2020 \\
Accepted March 23, 2020 \\
Available online February 15, 2021 \\
\hline Keywords: \\
Amino acids \\
Schiff base \\
Methionine \\
Rumen protection \\
Lysine \\
\hline Correspondence: \\
M. Mazinani \\
mm5001@ msstate.edu
\end{tabular}

\begin{abstract}
The goal of this study was to modify three steps method for measuring protection rate of amino acids which has smaller size than nylon bag pores. To prepare the protected amino acids by the Schiff base method, each of the essential amino acids (methionine and lysine) in the aqueous solvent were brought to isoelectric $\mathrm{pH}$ and then reacted with the same molar ratio of aldehydes the reaction was refluxed for 30 minutes to 6 days (depending on the type of aldehyde used). The three-step in vitro method was used to estimate rumen insoluble protein in the rumen. In the manufacture of protected amino acid ligands, compounds with methionine amino acid had higher efficiency than lysine compounds and also glutaraldehyde ligands showed higher production efficiency compared to benzaldehydes. The glutaraldehyde lysine ligand showed the lowest release after $2 \mathrm{~h}$ of incubation in the rumen medium. At time 4 the methionine benzaldehyde ligand had the lowest release. Benzaldehyde had the lowest release at time 6 and 8. According to the results of this table, Lysine benzaldehyde had better resistance to different phases and methionine benzaldehyde had the lowest release rate compared to the other ligands. Based on this study, it can be concluded that the use of chemical methods to protect amino acids can be applied.
\end{abstract}

DOI: $10.33899 /$ ijvs.2020.126756.1371, (C2021, College of Veterinary Medicine, University of Mosul.

This is an open access article under the CC BY 4.0 license (http://creativecommons.org/licenses/by/4.0/).

\section{Introduction}

Ruminants, like other animals, need essential amino acids (EAA) to provide their needs for protein. Failure to provide EAA can reduce the performance of the animal and may even affect the health. knowing amino acid metabolism in rumen is important because ruminants need both rumen amino acids (microbial protein) and amino acids derived from food to meet their needs. Only a small fraction of the protein consumed by the animals pass through the rumen the rest of that is either broken down into microbial protein, or after hydrolysis, deamination occurs and its amino acids breakdown to ammonia and carbon skeleton. Therefore, supplying free essential amino acids for ruminants by adding to the diet is not successful. Because researches have shown the presence of microorganisms in the rumen will degrade amino acid sources such as lysine and methionine (1). The presence of microorganisms in the rumen, despite being useful for synthesis many amino acids and vitamins and other rules like assisting in the digestion of fiber, can have a negative effect on using essential amino acids, and especially in high-yielding animals that may need more essential amino acids (2).

One way to balance animal diet is to add these amino acids a protected form against rumen degradation but degradable in post-rumen. Previous researches have shown that it is possible to protect amino acids against rumen microbial digestion by physical protecting methods. Schwab showed that several methods have been evaluated to protect amino acids from ruminal degradation. Protection of amino acids is usually done by mechanical and physical methods $(2,3)$. The first method is $\mathrm{pH}$ sensitive encapsulation and has been used to encapsulate lysine and methionine (4). These polymers are resistant in rumen $\mathrm{pH}$ but breakdown when 
exposed to abomasal $\mathrm{pH}$. Some of these products may be ineffective when used with mixed diet or corn silage. Depending on the ruminal $\mathrm{pH}$, efficacy of these products has limited in feeding diets with low ruminal $\mathrm{pH}$ (such as high concentrated diets). Since the rumen $\mathrm{pH}$ is between 5.5 and 7 and there is a significant difference between the $\mathrm{pH}$ of the rumen and post rumen parts of intestinal track which is between 2 and 3 . The pH-sensitive polymer coats are used based on this $\mathrm{pH}$ difference. However, despite the high cost, making such capsule has its disadvantages. For example, any type of rumen-resistant coating may be damaged during chewing, feed processing, and rumination. If this damage happens during mixing and processing of the diet, it will breakdown the amino acid in the rumen (5).

The second way for protecting amino acids is Encapsulation with Neutral Lipid. Researchers of South Dakota conducted several studies using fatty acid capsules $58 \%$ and methionine $30 \%$ and observed variable results in improving milk production (5). They concluded that encapsulation of methionine improves its availability. New Products have now been developed by including calcium salts containing fatty acids. The potential problem with this method is that the amino acid can be overprotected, therefore complexes that are extremely neutral in the rumen can be indigestible in the small intestine, so there is a constant competition between good rumen protection and bioavailability. This method is a simple procedure, but the results are unsatisfactory, probably due to the low biodegradability the protected amino acids in the small intestine $(6,7)$.

Production of amino acid analogs and their derivatives is the other solution for protecting amino acids. Methionine hydroxy analogue (MHA) is the most important protected form of methionine studied. St Pierre et al. (8) reported that more than $70 \%$ of the initial concentration of MHA and only $15 \%$ of diethyl methionine remained after $12 \mathrm{~h}$ of incubation with rumen bacteria. Alimith, a liquid form of rumen MHA, was similar to methionine-resistant solid hydroxy analogues (6). In the early 1970s, it was hypothesized that amino acid derivatives (a free amino acid with a chemical blocking group added to the alpha-amine group or changed to an acyl group) or analogs, such as the substitution of the alpha-amine group with Non-nitrogen group may alter resistance to rumen degradation and absorbed in the small intestine. Many evidences point to increased bacterial protein synthesis, increased number of protozoa, increased fiber digestion, increased rumen fat synthesis, milk production, milk fat percentage, in lactating using MHA. Increases in milk production and milk fat percentage occurred mostly in early lactation cows and in herds using high percentages of concentration feed (9). But Results of using this product in other studies were variable. Therefore, manufacturing protected commercial amino acids with good quality is difficult. Researchers who have been researching this have been aware of this problem for years. It is well known; recent products are still far from ideal protected amino acids. Clearly, achieving a quality and sustainable product requires a lot of refinement of current products.

Schiff bases are products containing carbonyl and amine groups that were first reported by Schiff in 1864 and in the present study were protected by amino acids. In the last two decades, Schiff bases as chelating ligands have played a key role in the coordination chemistry of the intermediate metals as well as the major group metals. These ligands can easily form stable complexes with most intermediate metal ions. These ligands are often derived from direct synthetic pathways with good efficiency and high purity. The reason that these ligands are more favored than the other ligands for the coordination chemistry is related to their electronic properties and their good solubility in common solvents, their easy accessibility and their wide structural diversity (10). According to the above description, the purpose of this study was to produce protected amino acids against degradation in the rumen without polymer coatings problems with higher bioavailability.

\section{Materials and method}

\section{Making Schiff base ligands}

To prepare the protected amino acids by the Schiff base method, each of the essential amino acids (methionine and lysine) in the aqueous solvent were brought to isoelectric $\mathrm{pH}$ and then reacted with the same molar ratio of aldehydes the reaction was refluxed for 30 minutes to 6 days (depending on the type of aldehyde used). After that solution had cooled overnight, the contents were transferred to a funnel. The obtained sediments were separated and placed in desiccator for drying. The final product was an ester of amino acids, which resulted from the reaction of lysine and methionine with 2 different aldehydes, producing 4 products. All compounds synthesized in these experiments were identified by physico-chemical methods, spectroscopy and melting point detector. Identifying ligands was recorded by magnetic resonance spectroscopy (HNMR) and (CNMR) spectroscopy Avance $300 \mathrm{MHz}$ in DMSO solvent at $25^{\circ} \mathrm{C}$. The structure of each ligand was plotted using ChemDrow software.

\section{Modified 3-step in vitro method}

The three-step in vitro method was used to estimate rumen insoluble protein in the rumen (11) and this method has been used by NRC 2001 (12) as the reference method. The reference method uses nylon bags to measure the amount of released amino acid, but in the present study due to the smaller size of the particles than pore diameter of the bags and their rapid passage through the bags as soon as they were in the liquid phase, the bag was not used. The Schiff band created between amino acid and aldehyde, free amino acid and free aldehyde was used as a marker to identify the amount of released amino acid. 


\section{Statistical Analysis}

Data were analyzed as a one-way ANOVA using GLM procedure of SAS 9.1. Amino acid treatments were considered the only sources of variation. In the first step, the amino acids were reacted with aldehyde groups by reflux method and then the molecular weights of each ligand were measured using melting point device (Thermos 9300) and mass spectroscopy. Manufactured product efficiency was also obtained by the amount of product produced divided by theoretical calculations of the actual product quantity. The structure of each ligand was plotted using ChemDrow software, the results of which are presented in figure 1.

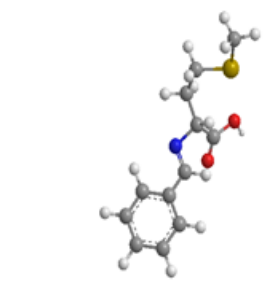

Methionine Benzaldehyde ligand Molecular Weight: 273.08 Efficiency: 91.61

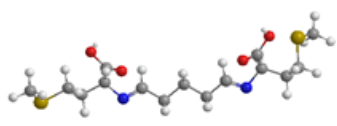

Methionine Glutaraldehyde ligand Molecular Weight: 362.51 Efficiency: 77.09

Figure 1: Chemical analysis of the ligands products.

\section{Results}

In the manufacture of protected amino acid ligands, compounds with methionine amino acid had higher efficiency than lysine compounds and also Glutaraldehyde ligands showed higher production efficiency compared to benzaldehydes. There was a slight difference between the experimental and theoretical frequencies, which was related to the coefficient of vibrational frequencies at the theoretical level, that were not applied here. The bond length as well as the bond angle of the ligands were in good agreement with the experimental and theoretical structure. The molar conductance of these ligands was measured in ethanol solvent, the highest molar conductance was observed in the benzaldehyde methionine ligand $108.88 \mathrm{~cm}^{3} / \mathrm{mol}$ and the lowest amount was in the methionine ligand $67.17 \mathrm{~cm}^{3} / \mathrm{mol}$. This amount of molar conductance indicates that these compounds had electrolyte bonds. The combined spectroscopic results of methionine benzaldehyde, lysine benzaldehyde confirmed the presence of two isomers in equilibrium.

\section{Measurement of release of ligands produced by a three- step method}

In this step, the release rate of conserved amino acids in each of the ruminal, abdominal and intestinal phases was artificially evaluated using a modified three-step method, the results are shown in table 1.

Time $0-8$ refers to the rumen phase, 10 to 9 abomasal phases and 34 was intestinal phases. The purpose of this part of the experiment was to estimate the rate of releasing amino acid in different $\mathrm{pHs}$. In fact, the goal for these products was to be constant in the rumen phase and released in the postrumen phase, i.e., the abdomen and the intestine, which changes depending on the $\mathrm{pH}$ of the environment. According to table 1 there is a significant difference between the ligands at all times. The glutaraldehyde lysine ligand showed the lowest release after $2 \mathrm{~h}$ of incubation in the rumen medium. At time 4 the methionine benzaldehyde ligand had the lowest release. Benzaldehyde had the lowest release at time 6 and 8 . According to the results of this table, Lysin benzaldehyde had better resistance to different phases and methionine benzaldehyde had the lowest release rate compared to the other ligands.

Table 1: Three step test of protected amino acids release

\begin{tabular}{lcccccc}
\hline Time & $\begin{array}{c}\text { Methionine } \\
\text { benzaldehyde }\end{array}$ & $\begin{array}{c}\text { Lysin } \\
\text { glutaraldehyde }\end{array}$ & $\begin{array}{c}\text { methionine } \\
\text { glutaraldehyde }\end{array}$ & $\begin{array}{c}\text { Lysin } \\
\text { benzaldehyde }\end{array}$ & SEM & P value \\
\hline 2 & $8.55^{\mathrm{b}}$ & $7.52^{\mathrm{b}}$ & $12.67^{\mathrm{a}}$ & $11.7^{\mathrm{a}}$ & 0.69 & 0.0001 \\
4 & $13.78^{\mathrm{b}}$ & $15.75^{\mathrm{b}}$ & $19.25^{\mathrm{a}}$ & $19.5^{\mathrm{a}}$ & 3.10 & 0.0001 \\
6 & $17.48^{\mathrm{b}}$ & $19.25^{\mathrm{b}}$ & $21.75^{\mathrm{a}}$ & $23.12^{\mathrm{a}}$ & 2.02 & 0.0001 \\
8 & $19.56^{\mathrm{b}}$ & $25.42^{\mathrm{ab}}$ & $24.15^{\mathrm{a}}$ & $39.04^{\mathrm{a}}$ & 3.15 & 0.0001 \\
9 & $64.53^{\mathrm{b}}$ & $67.24^{\mathrm{b}}$ & $64.53^{\mathrm{b}}$ & $70.15^{\mathrm{a}}$ & 1.10 & 0.0001 \\
10 & $70.99^{\mathrm{d}}$ & $78.52^{\mathrm{c}}$ & $75.65^{\mathrm{b}}$ & $84.16^{\mathrm{a}}$ & 1.40 & 0.0001 \\
34 & $75.42^{\mathrm{b}}$ & $80.04^{\mathrm{c}}$ & $77.17^{\mathrm{bc}}$ & $92.02^{\mathrm{ab}}$ & 1.55 & 0.0001 \\
\hline
\end{tabular}

The same letters mean non -significant differences, the different letters mean significant differences $(\mathrm{P}<0.05)$. 


\section{Discussion}

In the new NRC 2001 (12) model, the intestinal digestibility of RUP sources is considered to be different depending on the protein source, but this model does not consider the amino acids differences. There is limited information about the differences in intestinal digestion of different amino acids as they are difficult to estimate in ruminant animals. There are in vivo methods for measuring RUP-AA intestinal digestion (13), but in vitro methods can also be used to estimate RUP-AA intestinal digestibility of food sources. The most common method used for this purpose is the three-step method of Calsamiglia and Stern (14), although RUP-AA digestibility was not measured in this method. The three steps mentioned in this procedure include: 1) ruminal incubation, 2) digestion in pepsin, and 3) digestion in pancreatin. Gargalo et al. (15) also modified the three-step method to measure RUP-AA digestibility. In this method, RUP sources are poured into nylon bags and placed in digestive enzymes that provide the measurement of residual undigested material. They then measure the amount of amino acid remaining in the bag, and RUP-AA digestibility can be expressed as the percentage of amino acid disappearance of each bag. Other researchers used different markers to estimate the amount of amino acid digestibility by in vivo and in vitro methods (16). The method of measuring amino acid released in the present study was changed due to the difference in the products with other commercially available amino acids. The present study, due to the small size of the particles and their rapid passage through the bag as soon as they were in the liquid phase, the bag was not used and the Schiff band created between amino acid and aldehyde, free amino acid and free aldehyde was used as a marker to identify the amount of released amino acids. In fact, the goal for these products was being constant in the rumen phase and released in the post-rumen phase, i.e., the abdomen and the intestine, which changes depending on the $\mathrm{pH}$ of the environment. According to Table 2 there is a significant difference between the ligands at all times. The glutaraldehyde lysine ligand showed the lowest release after 2 hours of incubation in the rumen medium. At time 4 the methionine benzaldehyde ligand had the lowest release. Benzaldehyde had the lowest release at time 6 and 8 . According to the results of this table, Lysin benzaldehyde had better resistance to different phases and methionine benzaldehyde had the lowest release rate compared to the other ligands. The stability of commercially protected lysine (AjiPro®-L) was more than $90 \%$ in the ruminal phase, and in the post-ruminal phase incubated for 30 hours the rate of lysine release was $20 \%$ (17).

Based on this phase of the research, it was concluded that using three-step buffer-based method had the advantages like no need for a cannulated cow and therefore easy to perform, although the solutions required are somewhat expensive. On the other hand, it requires less labor and can also be used to determine amino acid release. Because in some cases nylon bags cannot use for commercial protected amino acids that their particle size is smaller than the bag pore diameter.

\section{Conclusion}

Based on this study, it can be concluded that the use of chemical methods for protecting amino acids can be applied. In most of the previous studies three step method was used by in situ and in vitro parts but in recent study three step method was modified and had some benefits. In vitro results showed that the lowest release in post-ruminal phases was related to methionine and glutaraldehyde lysine treatments, therefore they could be used as rumen protected amino acids.

\section{Conflict of interest}

The authors declare that there are no conflicts of interest regarding the publication of this manuscript.

\section{References}

1. Silva CM, Silva DL, Modolo LV. Schiff bases: A short review of their antimicrobial activities. J Adv Res. 2011;2(1):1-8. https://doi.org/10.1016/j.jare.2010.05.004

2. Mazinani M, Naserian AA, Rude B, Valizadeh R, Tahmasbi, A. Production of rumen-protected essential amino acids with chemical technique. Biosci Biotech Res Asia. 2019;16(04):789-795. https://doi.org/10.13005/bbra/2795

3. Schwab CG. Protected protein and amino acids for ruminants: Biotechnology in animal feed and animal feeding. Germany: Press Weinheim; $1995 . \quad 115-141 \quad \mathrm{p}$. https://doi.org/10.1002/9783527615353.ch7

4. Zamani F, Zendehdel M, Mobinikhaledi A, Azarkish M. Complexes of N,N-bis (salicylidene)4,5-dimethyl-1,2-phenylenediamine immobilized on porous nanomaterials: Synthesis characterization and study of their antimicrobial activity. Micropor Mesopor Material. 2015;212:18-27. https://doi.org/10.1016/j.micromeso.2015.02.052

5. Schwab CG, Huhtanen $P$, Hunt $C$, Hvelplund T. Nitrogen requirements of cattle: Nitrogen and phosphorus nutrition of cattle. Wallingford: CABI Publishing; 2005. $13-70$ p. https://doi.org/10.1079/9780851990132.0000

6. Socha MT, Putman DE, Garthwaite BD, Whitehouse NL, Kierstead NA, Schwab CG, Ducharme GA, Robert JC. Improving intestinal amino acid supply of pre- and postpartum dairy cows with rumenprotected methionine and lysine. J Dairy Sci. 2005;88: 1113-1126. https://doi.org/10.3168/jds.S0022-0302(05)72778-8

7. Mazinani M, Naserian AA, Mesgaran MD, Valizadeh R. Effects of adding coated urea on in vitro gas production of dairy cow. Biosci Biotech Res Asia. 2018;15(2):343-350. https://doi.org/10.13005/bbra/2638

8. St-Pierre NR, Sylvester JT. Effects of 2-hydroxy-4-(methylthio) butanoic acid (HMB) and its isopropyl ester on milk production and composition by Holstein cows. J Dairy Sci. 2005;88:2487-2497. https://doi.org/10.3168/jds.S0022-0302(05)72926-X

9. Redifer CA. Evaluation of peri-partum supplementation of methionine hydroxy analog on cow-calf performance. 2018. https://doi.org/10.1093/jas/sky404.200

10. Ashraf, M. A, Karamat, M, Abdul, W. Synthesis, Characterization and Biological Activity of Schiff Bases. 2011. International Conference on Chemistry and Chemical Process. https://doi.org/10.3109/01480545.2015.1017882 
11. Calsamiglia S, Stern MD. A three-step in vitro procedure for estimating intestinal digestion of protein in ruminants. J Anim Sci. 1995;73:14591465. https://doi.org/10.2527/1995.7351459x

12. NRC. Nutrient requirements of dairy cattle. $7^{\text {th }}$ ed. Washington: National Academy Press; 2001. 300-450 https://doi.org/10.17226/9825

13. Mazinani, M., Naserian, A.A., Rude, B.J., Tahmasbi, A.M. and Valizadeh, R., 2020. Effects of feeding rumen-protected amino acids on the performance of feedlot calves. JAVAR, 7(2), p.229. https://10.5455/javar.2020.g414

14. Calsamiglia S, Stern MD. A three-step in vitro procedure for estimating intestinal digestion of protein in ruminants. J Anim Sci. 1995;73:14591465. https://doi.org/10.2527/1995.7351459x

15. Gargallo SS, Calsamiglia A, Ferret A. Technical note: A modified three-step in vitro procedure to determine intestinal digestion of proteins. J Anim Sci. 2006;84:2163-2167. https://doi.org/10.2527/jas.2004-704

16. Schasteen CS, Wu J, Schulz MG, Parsons CM. Correlation of an immobilized digestive enzyme assay with poultry true amino acid digestibility for soybean meal. Poult Sci. 2007;86:343-348. https://doi.org/10.1093/ps/86.2.343

17. Whitehouse NL. Using the plasma free amino acid dose response method to determine metabolizable protein concentrations of lysine and methionine in rumen protected supplements [PhD dissertation]. University of New Hampshire. 150 p. 2016. https://doi.org/10.3168/jds.2017-12695

\section{استخدام طريقة قاعدة شيف لحماية الأحماض الأمينية وطريقة محورة خارج الجسم لقياس الاحماض الاضفيفة الامينية

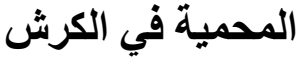

\author{
م. مازيناني'، أ.أ. ناسيريان'، ب رودي'، ر. فاليز ادي' و أ. تهماسبي'

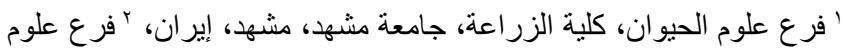 \\ الحيوان، كلية الزر اعة، جامعة مسسبي، الو لايات المتحدة الامريكية
}

الخلاصة

هدفت الدراسة الحالية الى تحوير طريقة الخطوات الثلاث لقياس معدل الحماية للاحماض الأمينية صغيرة الحجم (والتي بامكانها المرور من ثقوب غشناء النايلون). ولتحضير الأحماض الأمينية المحمية بطريقة

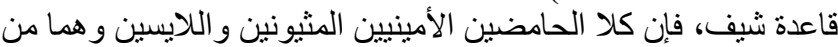

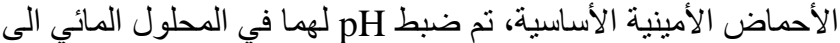

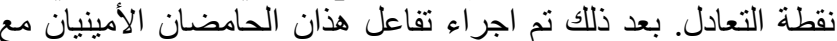

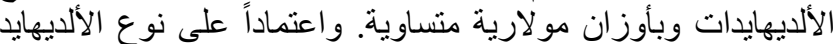

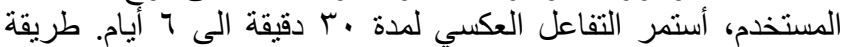

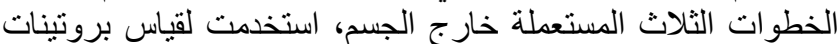

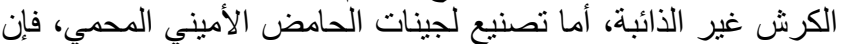

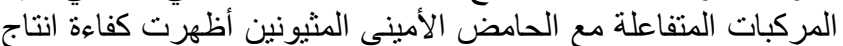

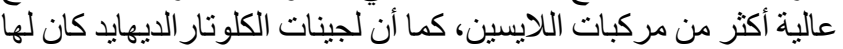

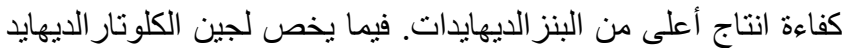

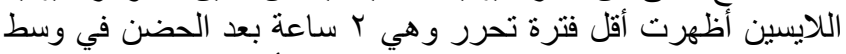

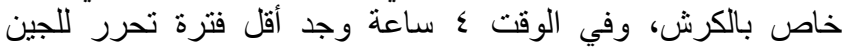

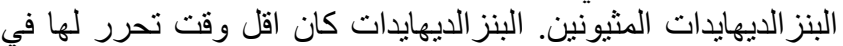

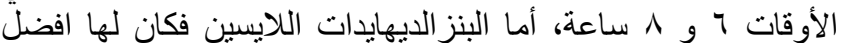

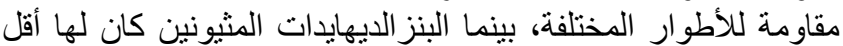

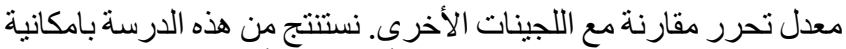
استخدام الطرق الكيميائية في حماية الأحماض الأمينة فينية. 